\title{
Long-Term Outcomes in Percutaneous Radiofrequency Ablation for Histologically Proven Colorectal Lung Metastasis
}

\author{
Jim Zhong' ${ }^{1}$ Ebrahim Palkhi ${ }^{1} \cdot$ Helen $\mathrm{Ng}^{2} \cdot$ Kevin Wang ${ }^{2} \cdot$ Richard Milton $^{3}$ • \\ Nilanjan Chaudhuri $^{3} \cdot$ James Lenton $^{1} \cdot$ Jonathan Smith $^{1} \cdot$ Bobby Bhartia $^{1}$. \\ Tze Min Wah ${ }^{1}$ (D)
}

Received: 5 May 2020/Accepted: 5 August 2020/Published online: 18 August 2020

(C) The Author(s) 2020

\begin{abstract}
Introduction To evaluate the long-term outcome of imageguided radiofrequency ablation (RFA) when treating histologically confirmed colorectal lung metastasis in terms of overall survival (OS), progression-free survival (PFS) and local tumour control (LTC).

Materials and Methods Retrospective single-centre study. Consecutive RFA treatments of histologically proven lung colorectal metastases between 01/01/2008 and 31/12/14. The primary outcome was patient survival (OS and PFS). Secondary outcomes were local tumour progression (LTP) and complications. Prognostic factors associated with OS/ PFS were determined by univariate and multivariate analyses.
\end{abstract}

Electronic supplementary material The online version of this article (https://doi.org/10.1007/s00270-020-02623-1) contains supplementary material, which is available to authorized users.
Results Sixty patients (39 males: 21 females; median age 69 years) and 125 colorectal lung metastases were treated. Eighty percent $(n=48)$ also underwent lung surgery for lung metastases. Mean metastasis size $(\mathrm{cm})$ was $1.4 \pm 0.6$ (range 0.3-4.0). Median number of RFA sessions was 1 (1-4). During follow-up (median 45.5 months), 45 patients died $(75 \%)$. The estimated OS and PFS survival rates at 1 , $3,5,7,9$ years were $96.7 \%, 74.7 \%, 44.1 \%, 27.5 \%, 16.3 \%$ (median OS, 52 months) and 66.7\%, 31.2\%, 25.9\%, 21.2\% and $5.9 \%$ (median PFS, 19 months). The LTC rate was $90 \%$ with 6 patients developing LTP with 1-, 2-, 3- and 4-year LTP rates of $3.3 \%, 8.3 \%, 10.0 \%$ and $10.0 \%$. Progression-free interval $<1$ year $(P=0.002, \mathrm{HR}=0.375)$ and total number of pulmonary metastases $(\geq 3)$ treated $(P=0.037, \quad$ HR $=0.480)$ were independent negative prognostic factors. Thirty-day mortality rate was $0 \%$ with no intra-procedural deaths.

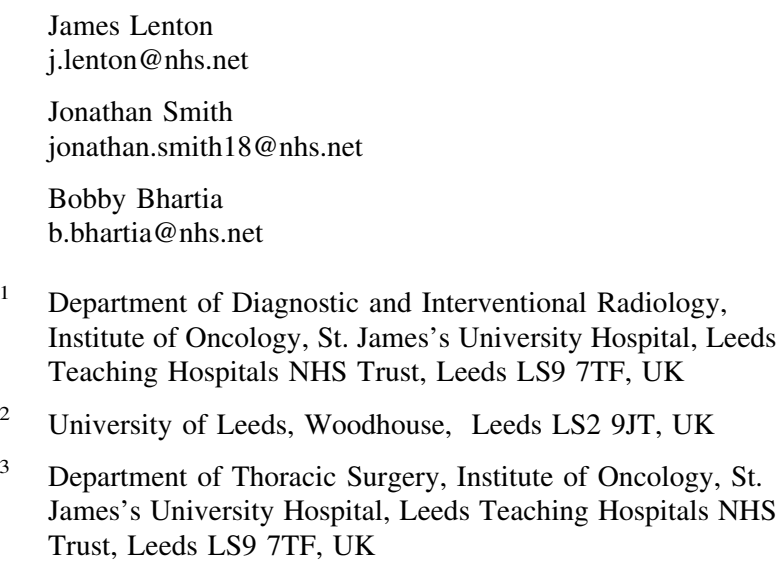


Conclusion The long-term OS and PFS following RFA for the treatment of histologically confirmed colorectal lung metastases demonstrate comparable oncological durability to surgery.

Keywords Radiofrequency ablation · Colorectal . Metastases · Lung · Overall survival · Progressionfree survival

\section{Introduction}

Colorectal cancer is the second most common cause of cancer death worldwide [1]. A quarter of colorectal patients who undergo curative resection will develop distant metastases with the lung being the second most common site [2]. A large epidemiological study of colorectal cancer patients with lung metastases found 3- and 5-year survival rates of $1.3 \%$ and $6.9 \%$, highlighting the poor prognosis in this cohort of patients if left untreated [3]. When the metastatic disease is localised to two or less visceral sites (oligometastatic disease), a potentially curative approach exists. Localised resection of lung metastases is the widely recognised standard of care for patients with oligometastatic disease from colorectal cancer despite the lack of randomised control trial (RCT) data comparing treatment options [4].

Percutaneous image-guided thermal ablation with radiofrequency ablation (RFA) has been widely used in the last decade and is established as a potential alternative to surgical resection [5, 6]. It is the most suitable for patients with small $(<2 \mathrm{~cm})$ lung metastases and in those who may not be a surgical candidate due to their comorbidities [5, 7]. RFA of lung metastases offers a minimally invasive, repeatable treatment, with better preservation of lung function treatment when compared to surgical resection [8]. No studies directly compare RFA with surgery, but published results suggest local control and survival rates similar to surgery $[8,9]$. Long-term survival data on RFA remain limited when compared to the surgical literature, making it difficult to draw definitive conclusions on the long-term oncological durability of the treatment [10].

The aim of this study was to report the long-term survival outcomes of image-guided RFA when treating histologically confirmed colorectal lung metastasis in terms of overall survival (OS), progression-free survival (PFS) and local tumour control (LTC).

\section{Methods}

\section{Study Population}

The study involved retrospective analysis of a prospectively collected database. It was performed under a waiver of informed consent and ethics approval by the institutional review board.

All consecutive image-guided pulmonary RFA procedures undertaken between 1 January 2008 and 31 December 2014 were reviewed. Inclusion criteria were treatment for oligometastatic colorectal metastases with histological confirmation either from surgical resection or percutaneous image-guided biopsy at the time of or prior to ablation of at least one lung lesion. Patients without histological confirmation and those with other primary pathologies were excluded from this study.

All treatments were performed in a single regional tertiary cancer centre. The lung metastases treatment decisions were made by the local multidisciplinary team (MDT) which included thoracic surgery and interventional oncology. Treatment decisions were made on the basis of the likelihood of technical success, preservation of lung function, the requirement to obtain histological confirmation of disease, the performance status of the patient and the patient's choice. At the time of the study, stereotactic radiotherapy (SABR) had not been commissioned for the treatment of lung metastases.

\section{RFA Procedure and Follow-up}

All treatments were targeted with computed tomography (CT) guidance and performed under general anaesthesia (GA). The RFA device utilised a unipolar multi-tined expandable applicator that delivered alternating RF current controlled by the impedance in the RF treatment algorithm (LeVeen; Boston Scientific, Natick, MA).

The aim of treatment was to ablate the lung metastasis with a minimum of a 5-mm treatment margin. Lesions in the same lung were treated in a single session, but contralateral lesions were treated at a different treatment session due to the risk of pneumothorax. An immediate postRFA unenhanced chest CT was obtained after RFA electrode removal to assess for pneumothorax. All pneumothoraces were observed for up to $10 \mathrm{~min}$ under GA, and enlargement was considered an indication for drainage. All patients were observed overnight following RFA for potential complications, and a chest radiograph was performed $4 \mathrm{~h}$ post-RFA and before discharge to ensure there was no delayed or worsening pneumothorax.

An unenhanced chest CT scan was performed at 1, 3, 6, $12,18,24$ months and then yearly after the RFA to 
evaluate the local control rate, the presence of new metastatic disease within the lungs and for any complications. All patients with local tumour progression were reassessed by consensus of the local MDT for suitability of surgical resection or repeat image-guided thermal ablation eligibility.

\section{Definitions of Study Outcome Measures}

Standardised definitions of outcomes and grading of complications were applied [5, 11, 12].

Technical success of RFA was defined as the complete coverage of the tumour by the ablation zone of ground glass opacity (GGO), with at least a 5-mm ablative treatment margin seen on the $\mathrm{CT}$ imaging at the end of the procedure. GGO was defined as increased opacification of lung, with preservation of bronchial and vascular margins as per the Fleischner Society [13]. Technical failure was defined as incomplete tumour ablation with the presence of residual tumour at the end of the RFA treatment session not encompassed within the ablation zone or with less than 5-mm ablative treatment margin.

Local tumour progression (LTP) was defined by the appearance of tumour foci inside or at the edge of the ablation zone during imaging follow-up, provided that complete ablation with adequate margins could be documented with a previous study.

Time to progression (TTP) is the time interval between first RFA and local or distant disease progression. Its associated metric is progression-free survival (PFS) defined as the interval from RFA to local or distant disease progression or death (from any cause); both are measures of oncologic efficacy rather than technical success. Overall survival (OS) was defined as the time from first treatment with RFA to death (from any cause). RFA-related adverse events were assessed according to the CIRSE classification system [12].

\section{Statistical Analysis}

Statistical analyses were performed using SPSS software (version 23.0; IBM Corp, Armonk, New York). KaplanMeier method used to evaluate OS and PFS with $95 \%$ confidence intervals (CI) was calculated. To detect prognostic factors the following variables were collected: sex (male or female), progression-free interval $(<1$ year or $\geq 1$ year), history of lung surgery for metastases (yes or no), total number of pulmonary metastases treated by RFA and surgery $(<3$ or $\geq 3)$, largest size of ablated tumour $(<2 \mathrm{~cm}$ or $\geq 2 \mathrm{~cm}$ ), history of liver metastases (yes or no) and chemotherapy prior to RFA (yes or no) (Supplementary material). Univariate analyses were performed by the log-rank test to compare the survival rates (for both OS and
PFS) between each pair of groups/prognostic factors (Supplementary material). Multivariate analyses to determine the independent prognostic factors were performed using the Cox proportional-hazards model. For all analyses, a $P$ value of $<0.05$ was considered statistically significant.

\section{Results}

A total of 96 patients underwent RFA between 1 January 2008 and 31 December 2014. In total, 60 patients with histologically confirmed colorectal lung metastases $(n=125)$ treated by image-guided RFA were included in the retrospective analysis. Patient characteristics are displayed in Table 1. The 36 patients excluded were due to lack of histological confirmation of colorectal metastases or treatment for other disease pathologies. The mean metastasis size was $1.4 \mathrm{~cm}$. Standard deviation (SD) was $0.6 \mathrm{~cm}$ and ranges $0.3-4.0 \mathrm{~cm}$.

The median duration of follow-up after the initial image-guided RFA was 45.5 months (range 3-141).

Out of the 28 patients who had a history of colorectal liver metastases (Table 1), 27 had locoregional liver treatment with either liver ablation or resection for their colorectal metastases.

The maximum number of lung metastases treated with image-guided RFA was 9, and this patient had two separate treatment sessions to treat left lower lobe nodules $(n=5)$ followed by a further treatment session to treat the left upper lobe nodules $(n=4)$.

\section{Local Tumour Progression and Long-Term Survival Outcomes}

Out of 125 treated pulmonary metastases, the primary technical success rate in this cohort was $99.2 \%$. One patient had incomplete treatment of a metastasis (technical failure) and required a second RFA to successfully treat the residual disease. The overall technical success rate for this cohort of patients treated with image-guided RFA for their colorectal lung metastasis was $100 \%$

The overall LTC rate was $90 \%$ with $10 \%$ of the patients $(n=6)$ developing LTP with a median time to local progression of 18 months (range 10-26) from the initial treatment. The LTP rate was $3.3 \%$ at 1 year, $8.3 \%$ at 2 years, $10.0 \%$ at 3 years and $10.0 \%$ at 4 years.

During the study review period (01/01/2008-31/12/ 2019), a total of 45 patients with colorectal lung metastasis treated with image-guided RFA $(75 \%)$ died. The causes were disease progression $(n=29)$, heart failure $(n=2)$, decompensated liver disease $(n=1)$ or unknown causes $(n=13)$. 
Table 1 Patient characteristics

\begin{tabular}{|c|c|}
\hline Characteristic & Value ( $\% /$ range) \\
\hline \multicolumn{2}{|l|}{ Age $(y)$} \\
\hline Median & $69(31-89)$ \\
\hline \multicolumn{2}{|l|}{ Sex } \\
\hline Male & $39(65 \%)$ \\
\hline Female & $21(35 \%)$ \\
\hline \multicolumn{2}{|l|}{ Site of primary cancer } \\
\hline Colon & $28(46.7 \%)$ \\
\hline Sigmoid & $5(8.3 \%)$ \\
\hline Rectum & $27(45 \%)$ \\
\hline \multicolumn{2}{|l|}{ History of lung surgery for metastases } \\
\hline Yes & $48(80 \%)$ \\
\hline No & $12(20 \%)$ \\
\hline \multicolumn{2}{|l|}{ Chemotherapy prior to RFA } \\
\hline Yes & $21(35 \%)$ \\
\hline No & $39(65 \%)$ \\
\hline \multicolumn{2}{|l|}{ History of colorectal liver metastases } \\
\hline Yes & $28(47 \%)$ \\
\hline No & $32(53 \%)$ \\
\hline Number of lesions treated with RFA & Total $=125$ \\
\hline Median & $2(1-9)$ \\
\hline Number of lesions treated with surgery & Total $=143$ \\
\hline Median & $2(1-10)$ \\
\hline Number of RFA sessions & Total $=82$ \\
\hline Median & $1(1-4)$ \\
\hline \multicolumn{2}{|l|}{ Maximum size of ablated tumour } \\
\hline $0-1 \mathrm{~cm}$ & $71(57 \%)$ \\
\hline $1-2 \mathrm{~cm}$ & $48(38 \%)$ \\
\hline $2-3 \mathrm{~cm}$ & $5(4 \%)$ \\
\hline $3-4 \mathrm{~cm}$ & $1(1 \%)$ \\
\hline
\end{tabular}

The Kaplan-Meier survival analysis for all patients ( $n=60$ ) found the median OS to be 52 months $(95 \% \mathrm{CI}$ 39.3-64.7) (Fig. 1). The 1-, 3-, 5-, 7- and 9-year overall survival rates were $96.7 \%, 74.7 \%, 44.1 \%, 27.5$ and $16.3 \%$.

Median PFS was 19 months (95\% CI 9.6-28.4) (Fig. 2). The 1-, 3-, 5-, 7- and 9-year progression-free survival rates were $66.7 \%, 31.2 \%, 25.9 \%, 21.2 \%$ and $5.9 \%$.

Univariate and multivariate analysis (detailed breakdown provided for each prognostic factor is provided in Supplementary Information) identified progression-free interval of less than one year to be significantly associated with worse $\operatorname{OS}(P=0.002$, hazard ratio 0.375$)$, and the total number of pulmonary metastases $(\geq 3)$ treated was significantly associated with worse PFS $(P=0.037$, hazard ratio 0.480$)$.

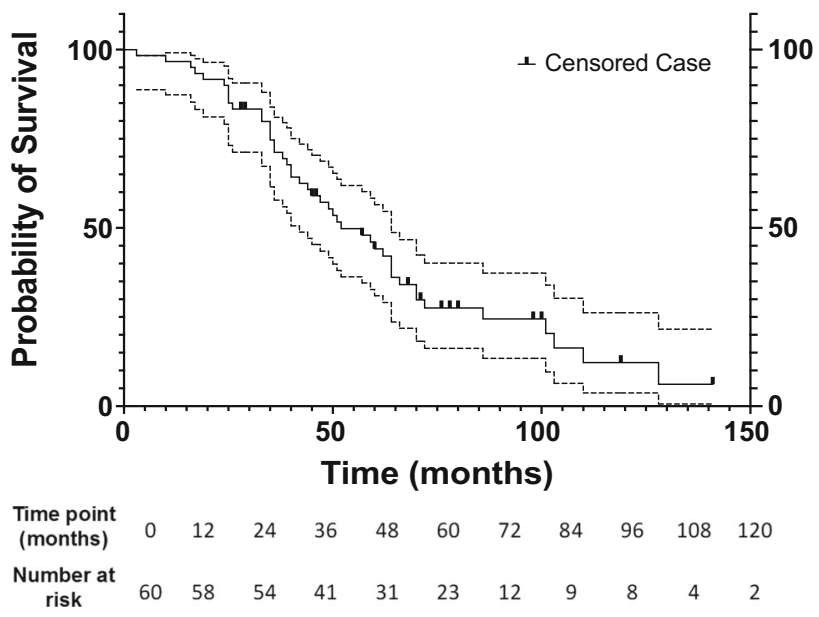

Fig. 1 Graph shows Kaplan-Meier overall survival estimate for all patients with metastasis to lung from colorectal carcinoma treated with RFA. Dotted lines represent $95 \%$ confidence intervals

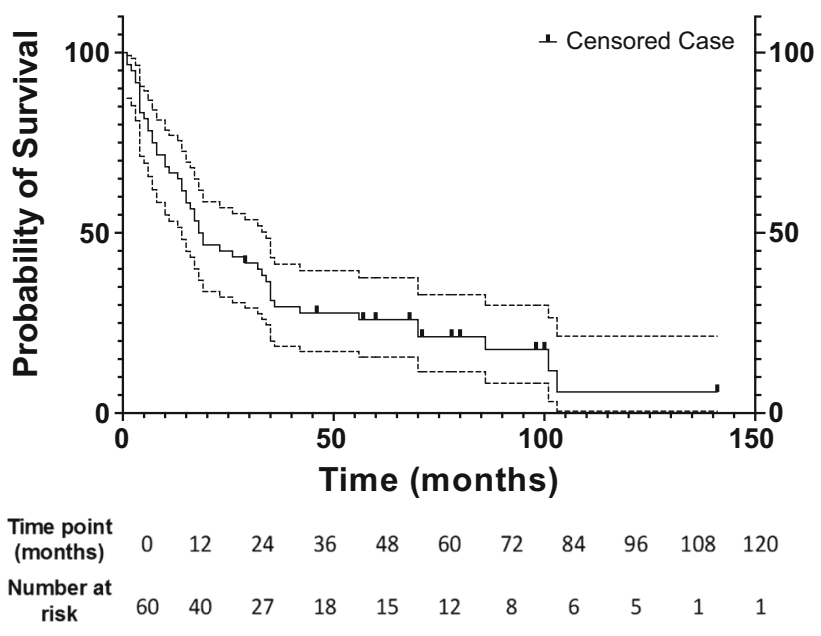

Fig. 2 Graph shows Kaplan-Meier progression-free survival estimate for all patients with metastasis to lung from colorectal carcinoma treated with RFA. Dotted lines represent $95 \%$ confidence intervals

\section{Adverse Events}

For this patient cohort, the 30-day post-RFA mortality rate was $0 \%$ with no intra-procedural deaths.

In total, 36 patients $(60 \%)$ developed a pneumothorax (Grade 1) following RFA, and all were diagnosed on the immediate postprocedural unenhanced chest CT. Of these patients, 18 required a CT-guided chest drain insertion to relieve the enlarging pneumothorax, while the remainder were managed conservatively with spontaneous resolution. Two (3\%) patients required a chest drain for a subsequent reactive effusion (Grade 2). Two patients (3\%) developed a post-RFA air leak requiring video-assisted thoracoscopic surgery (Grade 3). 


\section{Discussion}

A median overall survival of 52 months with a five-year OS and PFS of $44.1 \%$ and $25.9 \%$, respectively, is in line with existing literature. Few previous studies have examined long-term survival following RFA in colorectal metastases (Table 2) [14-18], and none included only patients with histological confirmation as in the current study. Although desirable, histological confirmation is not always feasible prior to treatment. A relevant clinical history with concordant imaging may sufficiently support an MDT decision to proceed with treatment. Biopsy at the time of ablation risks inducing haemorrhage or pneumothorax and may jeopardise accuracy of RF probe placement. One recently suggested option to mitigate these risks is to biopsy immediately after RFA which carries a diagnostic sampling rate of $90 \%$ [19].

The results of this current study support the findings of previous studies without comprehensive histological confirmation. A systematic review by Lyons et al. [20] included over 900 patients from 8 RFA studies on colorectal lung metastases and demonstrated OS rates at 5 years of $19.9 \%$ and PFS rates of $7 \%$. A more recent study by Matsui et al. published a more favourable 5-year OS rate of 52\% with a median OS of 67 months [15]. Differences in the outcomes data can reflect confounders within the different patient populations. The improved long-term survival observed in more recent studies is possibly attributable to advancement in chemotherapy for metastatic colorectal cancer in the neoadjuvant and palliative setting [21].

The LTC rate in this study was $90 \%$ and a median time to LTP of 18 months (3-26). This is consistent with other studies which quote a LTC rate of $69-87 \%$ [15, 22, 23]. The median time to LTP in the published RFA literature is variable [10]. Previous studies have quoted the median times to LTP in the range of 8.2-11.2 months; however, the ranges vary widely from 2.6 to 43.7 months [15, 23]. In the largest published RFA series by de Baère et al. [7], the 1-, 2-, 3- and 4-year local tumour progression (LTP) rates were $5.9 \% .8 .5 \%, 10.2 \%$ and $11 \%$, respectively. Our study confirms the finding that the majority of local recurrences occur within the first 2 years following treatment.

In terms of prognostic factors, this study confirms that the total number of pulmonary metastases $(\geq 3)$ treated with RFA and surgery is associated with worse PFS $(P=0.037)$. The number of metastases has also been found to a predictor of survival in other large retrospective RFA studies [7] and surgical series [24]. The current study confirmed a previously demonstrated lack of correlation between a history of treated liver metastases with survival $[17,23]$.

Surgical series (Table 3) have shown favourable longterm survival rates, and despite the absence of RCT data, resection is considered first-line treatment [4]. Surgical literature focuses on 5-year survival with estimates ranging between 38.3 and $71.3 \%$ [24-33]. The ablation literature frequently quotes $1-3$-year survival, but when reported the five-year survival after thermal ablation is less favourable compared to the surgical literature and the 5-year survival rates following RFA ranges between 19.9 and 57\% [7, 14, 15, 34-36]. A multi-centre surgical series [33] found 5-year disease-free and OS rates of $37.1 \%$ and $68.1 \%$ (compared to $30.4 \%$ and $44.1 \%$ in the current study), over a median follow-up of 65 months. The favourable survival rates may be partly attributable to patient selection criteria with a higher proportion (75\%) of patients with a solitary metastasis and only complete resections included in the results [33, 37]. Comparing ablation with surgical outcomes fails to recognize that these are frequently not mutually exclusive groups. Eighty percent of the patients in our study also had surgical resection for colorectal lung metastases. This is higher than other published cohorts, which varies from 45 to $53 \%[15,23]$. This is perhaps a reflection of a collaborative MDT approach where

Table 2 RFA studies of colorectal lung metastases reporting 5-year survival data

\begin{tabular}{|c|c|c|c|c|c|c|c|}
\hline \multirow[t]{2}{*}{ Authors } & \multirow[t]{2}{*}{ Year } & \multirow[t]{2}{*}{ Number of patients } & \multirow[t]{2}{*}{ Ablation modality } & \multicolumn{3}{|c|}{ Overall survival rates $(\%)$} & \multirow[t]{2}{*}{ Mean/median survival (months) } \\
\hline & & & & $1 \mathrm{y}$ & $3 y$ & $5 \mathrm{y}$ & \\
\hline Simon et al. [34] & 2007 & 18 & RFA & 87 & 57 & 57 & - \\
\hline Yamakado et al. [45] & 2009 & 78 & RFA & 84 & 56 & 35 & 38 \\
\hline Matsui et al. [15] & 2015 & 84 & RFA & 95.2 & 65 & 51.6 & 67 \\
\hline Ferguson et al. [35] & 2015 & 157 & RFA & 89 & 44 & 19.9 & 33.3 \\
\hline de Baère et al. [7] & 2015 & $566^{*}$ & RFA & 92.4 & 67.7 & 51.5 & 62 \\
\hline Vogl et al. [22] & 2016 & 41 & RFA & 76.9 & $\begin{array}{l}50.8 \\
(2 \mathrm{y})\end{array}$ & $\begin{array}{l}8 \\
(4 \mathrm{y})\end{array}$ & 24.2 \\
\hline Shi et al. [36] & 2017 & $43 *$ & RFA & 77 & 42 & 34 & - \\
\hline
\end{tabular}

The asterisk (*) highlights inclusion of non-colorectal lung metastases 
Table 3 Surgical studies focusing on colorectal lung metastases with reported 5-year survival data

\begin{tabular}{|c|c|c|c|c|c|c|}
\hline \multirow[t]{2}{*}{ Authors } & \multirow[t]{2}{*}{ Year } & \multirow[t]{2}{*}{ Number of patients } & \multicolumn{3}{|c|}{ Overall survival rates $(\%)$} & \multirow[t]{2}{*}{ Mean/median survival (months) } \\
\hline & & & $1 \mathrm{y}$ & $3 \mathrm{y}$ & $5 \mathrm{y}$ & \\
\hline Kanemitsu et al. [25] & 2004 & 313 & 90.4 & 53.0 & 38.3 & 38.4 \\
\hline Yedibela et al. [26] & 2006 & 153 & - & $\begin{array}{l}64 \\
(2 \mathrm{y})\end{array}$ & 37 & 39 \\
\hline Welter et al. [27] & 2007 & 169 & - & - & 39 & 47.2 \\
\hline Onaitis et al. [28] & 2009 & 378 & - & 78 & 56 & - \\
\hline Blackmon et al. [24] & 2012 & 229 & - & - & 55.4 & 70.1 \\
\hline Iida et al. [29] & 2013 & 1030 & - & - & 53.5 & 69.5 \\
\hline Hirosawa et al. [30] & 2013 & 266 & - & - & 56.5 & - \\
\hline Bolukbas et al. [31] & 2014 & 165 & - & - & 54 & 64 \\
\hline Sun et al. [32] & 2017 & 154 & - & - & 71.3 & - \\
\hline Okumura et al. [33] & 2017 & 785 & - & - & 68.1 & - \\
\hline
\end{tabular}

complete treatment of the lung metastases with preservation of lung function regardless of underlying fitness is one of the stated aims. Image-guided thermal ablation of lung metastases in our cancer centre acts as an adjunct rather than competitor to the existing surgical resection cancer service in this cohort of patients.

Although microwave ablation (MWA) has theoretical advantages over RFA, such as less heat sink effect and potentially more uniform ablation zones in a shorter time [22, 38-40], the LUMIRA RCT has found no statistically significant difference between MWA and RFA in terms of survival [41]. In 2019, a meta-analysis of 53 studies showed the 5-year OS rates for RFA-treated patients $(n=738)$ were higher compared with MWA-treated patients $(n=469)(P<0.001)$ and treatment with RFA was correlated with a longer median OS of 34.8 months compared to 18.7 for MWA [6]. Confounding factors may be that RFA is better known and has been used for longer, with more reproducible results, whereas MWA is a newer modality with smaller study sample sizes. Larger groups with longer follow-up periods are required before firm conclusions can be drawn.

Currently, no RCT exists that compares thoracic surgery versus image-guided ablation and will be difficult to achieve. The recent Pulmonary Metastasectomy in Colorectal Cancer (PulMiCC) trial (comparing surgery vs active monitoring) had to be stopped due to failure to recruit the required number of patients [44]. An RCT in the setting of colorectal lung metastases would also be of questionable value, given many patients receive multiple different treatment modalities throughout their course. Registries can provide evidence of the technical success and safety of ablation in the context of treating metastatic disease.
The limitations of this study were the retrospective single-centre design with a small sample size. Given that only patients with histological proven cancer were included, this may have biased the results towards better outcomes if comorbid patients were not subjected to biopsy due to the inherent small additional risks of lung biopsy.

\section{Conclusion}

The long-term OS and PFS following RFA for the treatment of histologically confirmed colorectal lung metastases demonstrate comparable oncological durability to surgery.

Funding This study was not supported by any funding.

\section{Compliance with Ethical Standards}

Conflict of interest The authors declare that they have no conflict of interest.

Informed Consent For this type of study formal consent is not required. This study was performed under a waiver of informed consent by the institutional review board.

Consent for Publication Consent for publication was obtained for every individual person's data included in the study.

Open Access This article is licensed under a Creative Commons Attribution 4.0 International License, which permits use, sharing, adaptation, distribution and reproduction in any medium or format, as long as you give appropriate credit to the original author(s) and the source, provide a link to the Creative Commons licence, and indicate if changes were made. The images or other third party material in this article are included in the article's Creative Commons licence, unless indicated otherwise in a credit line to the material. If material is not included in the article's Creative Commons licence and your intended use is not permitted by statutory regulation or exceeds the permitted 
use, you will need to obtain permission directly from the copyright holder. To view a copy of this licence, visit http://creativecommons. org/licenses/by/4.0/.

\section{References}

1. Bray F, Ferlay J, Soerjomataram I, Siegel RL, Torre LA, Jemal A. Global cancer statistics 2018: GLOBOCAN estimates of incidence and mortality worldwide for 36 cancers in 185 countries. CA Cancer J Clin [Internet]. 2018;68:394-424.

2. Manfredi S, Bouvier AM, Lepage C, Hatem C, Dancourt V, Faivre J. Incidence and patterns of recurrence after resection for cure of colonic cancer in a well defined population. Br J Surg [Internet]. 2006;93(1):1115-22.

3. Mitry E, Guiu B, Cosconea S, Jooste V, Faivre J, Bouvier AM. Epidemiology, management and prognosis of colorectal cancer with lung metastases: a 30-year population-based study. Gut [Internet]. 2010;59:1383-8.

4. Van Cutsem E, Cervantes A, Adam R, Sobrero A, Van Krieken JH, Aderka D, et al. ESMO consensus guidelines for the management of patients with metastatic colorectal cancer. Ann Oncol [Internet]. 2016;27(8):1386-422.

5. Venturini M, Cariati M, Marra P, Masala S, Pereira P, Carrafiello G. CIRSE standards of practice on thermal ablation of primary and secondary lung tumours. Cardiovasc Intervent Radiol. 2020;43(5):667-83.

6. Yuan Z, Wang Y, Zhang J, Zheng J, Li W. A meta-analysis of clinical outcomes after radiofrequency ablation and microwave ablation for lung cancer and pulmonary metastases. J Am Coll Radiol [Internet]. 2019;16(3):302-14.

7. De BT, Aupérin A, Deschamps F, Chevallier P, Gaubert Y, Boige $\mathrm{V}$, et al. Radiofrequency ablation is a valid treatment option for lung metastases : experience in 566 patients with 1037 metastases. Ann Oncol. 2015;26:987-91.

8. De BT, Tselikas L, Gravel G, Deschamps F. Lung ablation : best practice/results/response assessment/role alongside other ablative therapies. Clin Radiol. 2017;72(8):657-64.

9. Qi H, Fan W. Value of ablation therapy in the treatment of lung metastases. Thorac Cancer [Internet]. 2018;9(2):199-207.

10. Schlijper RCJ, Grutters JPC, Houben R, Dingemans AMC, Wildberger JE, Van RD, et al. What to choose as radical local treatment for lung metastases from colo-rectal cancer: surgery or radiofrequency ablation? Cancer Treat Rev [Internet]. 2014;40:60-7.

11. Ahmed M, Solbiati L, Brace CL, Breen DJ, Callstrom MR, Charboneau JW, et al. Image-guided tumor ablation: Standardization of terminology and reporting criteria-A 10-year update. Radiology [Internet]. 2014;273(1):241-60.

12. Filippiadis DK, Binkert C, Pellerin O, Hoffmann RT, Krajina A, Pereira PL. Cirse quality assurance document and standards for classification of complications: the cirse classification system. Cardiovasc Intervent Radiol [Internet]. 2017;40:1141-6.

13. Hansell DM, Bankier AA, MacMahon H, McLoud TC, Müller NL, Remy J. Fleischner society: glossary of terms for thoracic imaging. Radiology [Internet]. 2008;246(3):697-772.

14. Yamakado K, Hase S, Matsuoka T, Tanigawa N, Nakatsuka A, Takaki H, et al. Radiofrequency ablation for the treatment of unresectable lung metastases in patients with colorectal cancer: a multicenter study in Japan. J Vasc Interv Radiol [Internet]. 2007;18(3):393-8.

15. Matsui Y, Hiraki T, Gobara H, Iguchi T, Fujiwara H, Nagasaka T, et al. Long-term survival following percutaneous radiofrequency ablation of colorectal lung metastases. J Vasc Interv Radiol [Internet]. 2015;26:303-10.

16. Hiraki T, Gobara H, Iguchi T, Fujiwara H, Matsui Y, Kanazawa $\mathrm{S}$. Radiofrequency ablation as treatment for pulmonary metastasis of colorectal cancer. World J Gastroenterol. 2014;20(4):988-96.

17. Gillams A, Khan Z, Osborn P, Lees W. Survival after radiofrequency ablation in 122 patients with inoperable colorectal lung metastases. Cardiovasc Intervent Radiol [Internet]. 2013;36:724-30.

18. Fanucchi O, Ambrogi MC, Aprile V, Cioni R, Cappelli C, Melfi $\mathrm{F}$, et al. Long-term results of percutaneous radiofrequency ablation of pulmonary metastases: a single institution experience. Interact Cardiovasc Thorac Surg. 2016;23(1):57-64.

19. Tselikas L, de Baere T, Deschamps F, Hakimé A, Besse B, Teriitehau C, et al. Diagnostic yield of a biopsy performed immediately after lung radiofrequency ablation. Eur Radiol [Internet]. 2017;27:1211-7.

20. Lyons NJR, Pathak S, Daniels IR, Spiers A, Smart NJ. Percutaneous management of pulmonary metastases arising from colorectal cancer: a systematic review. Eur J Surg Oncol [Internet]. 2015;41:1447-555.

21. Kopetz S, Chang GJ, Overman MJ, Eng C, Sargent DJ, Larson DW, et al. Improved survival in metastatic colorectal cancer is associated with adoption of hepatic resection and improved chemotherapy. J Clin Oncol [Internet]. 2009;27:3677-83.

22. Vogl TJ, Eckert R, Naguib NNN, Beeres M, Gruber-Rouh T, Nour-Eldin NEA. Thermal ablation of colorectal lung metastases: retrospective comparison among laser-induced thermotherapy, radiofrequency ablation, and microwave ablation. Am J Roentgenol [Internet]. 2016;207:1340-9.

23. Petre EN, Jia X, Thornton RH, Sofocleous CT, Alago W, Kemeny NE, et al. Treatment of pulmonary colorectal metastases by radiofrequency ablation. Clin Colorectal Cancer [Internet]. 2013;12(1):37-44.

24. Blackmon SH, Stephens EH, Correa AM, Hofstetter W, Kim MP, Mehran RJ, et al. Predictors of recurrent pulmonary metastases and survival after pulmonary metastasectomy for colorectal cancer. Ann Thorac Surg [Internet]. 2012;94:1802-9.

25. Kanemitsu Y, Kato T, Hirai T, Yasui K. Preoperative probability model for predicting overall survival after resection of pulmonary metastases from colorectal cancer. $\mathrm{Br} \mathrm{J}$ Surg [Internet]. 2004;91(1):112-20.

26. Yedibela S, Klein P, Feuchter K, Hoffmann M, Meyer T, Papadopoulos T, et al. Surgical management of pulmonary metastases from colorectal cancer in 153 patients. Ann Surg Oncol [Internet]. 2006;13(11):1538-44.

27. Welter S, Jacobs J, Krbek T, Poettgen C, Stamatis G. Prognostic impact of lymph node involvement in pulmonary metastases from colorectal cancer. Eur J Cardio-thoracic Surg [Internet]. 2007;31(2):167-72.

28. Onaitis MW, Petersen RP, Haney JC, Saltz L, Park B, Flores R, et al. Prognostic factors for recurrence after pulmonary resection of colorectal cancer metastases. Ann Thorac Surg [Internet]. 2009;87:1684-8.

29. Iida T, Nomori H, Shiba M, Nakajima J, Okumura S, Horio H, et al. Prognostic factors after pulmonary metastasectomy for colorectal cancer and rationale for determining surgical indications: a retrospective analysis. Ann Surg [Internet]. 2013;257:1059-64.

30. Hirosawa T, Itabashi M, Ohnuki T, Yamaguchi N, Sugihara K, Kameoka S. Prognostic factors in patients undergoing complete resection of pulmonary metastases of colorectal cancer: a multiinstitutional cumulative follow-up study. Surg Today [Internet]. 2013;43:494-9.

31. Bölükbas S, Sponholz S, Kudelin N, Eberlein M, Schirren J. Risk factors for lymph node metastases and prognosticators of survival 
in patients undergoing pulmonary metastasectomy for colorectal cancer. Ann Thorac Surg [Internet]. 2014;97(6):1926-32.

32. Sun F, Chen L, Shi M, Yang X, Li M, Yang X, et al. Prognosis of video-assisted thoracoscopic pulmonary metastasectomy in patients with colorectal cancer lung metastases: an analysis of 154 cases. Int J Colorectal Dis [Internet]. 2017;32:897-905.

33. Okumura T, Boku N, Hishida T, Ohde Y, Sakao Y, Yoshiya K, et al. Surgical outcome and prognostic stratification for pulmonary metastasis from colorectal cancer. Ann Thorac Surg [Internet]. 2017;104(3):979-87.

34. Simon CJ, Dupuy DE, DiPetrillo TA, Safran HP, Grieco CA, Ng $\mathrm{T}$, et al. Pulmonary radiofrequency ablation: long-term safety and efficacy in 153 patients. Radiology [Internet]. 2007;243:268-75.

35. Ferguson J, Alzahrani N, Zhao J, Glenn D, Power M, Liauw W, et al. Long term results of RFA to lung metastases from colorectal cancer in 157 patients. Eur J Surg Oncol [Internet]. 2015;41:690-5.

36. Shi F, Li G, Zhou Z, Xu R, Li W, Zhuang W, et al. Microwave ablation versus radiofrequency ablation for the treatment of pulmonary tumors. Oncotarget [Internet]. 2017;8(65):109791-8.

37. Gonzalez M, Poncet A, Combescure C, Robert J, Ris HB, Gervaz P. Risk factors for survival after lung metastasectomy in colorectal cancer patients: a systematic review and meta-analysis. Ann Surg Oncol [Internet]. 2013;20:572-9.

38. Lubner MG, Brace CL, Hinshaw JL, Lee FT. Microwave tumor ablation: Mechanism of action, clinical results, and devices. J Vasc Interv Radiol [Internet]. 2010;21(8):S192-203.

39. Wolf FJ, Grand DJ, Machan JT, DiPetrillo TA, Mayo-Smith WW, Dupuy DE. Microwave ablation of lung malignancies: effectiveness, CT findings, and safety in 50 patients. Radiology [Internet]. 2008;247(3):871-9.
40. Lu Q, Cao W, Huang L, Wan Y, Liu T, Cheng Q, et al. CTguided percutaneous microwave ablation of pulmonary malignancies: results in 69 cases. World J Surg Oncol [Internet]. 2012;10:80.

41. Macchi M, Belfiore MP, Floridi C, Serra N, Belfiore G, Carmignani L, et al. Radiofrequency versus microwave ablation for treatment of the lung tumours: LUMIRA (lung microwave radiofrequency) randomized trial. Med Oncol [Internet]. 2017;34:96.

42. Soomro N, Lecouturier J, Stocken DD, Shen J, Hynes AM, Ainsworth HF, et al. Surveillance versus ablation for incidentally diagnosed small renal tumours: The SURAB feasibility RCT. Health Technol Assess [Internet]. 2017;21(81):1-68.

43. ClinicalTrials.gov [Internet]. Identifier: NCT01608165-A feasibility study for a multicentre randomised controlled trial to compare surgery with needle ablation techniques in people with small renal masses (4cm) (CONSERVE). 2012.

44. Treasure T, Farewell V, Macbeth F, Monson K, Williams NR, Brew-Graves C, et al. Pulmonary metastasectomy versus continued active monitoring in colorectal cancer (PulMiCC): a multicentre randomised clinical trial. Trials. 2019;20(1):718.

45. Yamakado K, Inoue Y, Takao M, Takaki H, Nakatsuka A, Uraki J. Long-term results of radiofrequency ablation in colorectal lung metastases: single center experience. Oncol Rep. 2009;22(4):885-9.

Publisher's Note Springer Nature remains neutral with regard to jurisdictional claims in published maps and institutional affiliations. 